\title{
THE LOCALIZATION OF SOME ACID PHOSPHATASES IN BRAIN TISSUE
}

\author{
BY \\ D. NAIDOO and O. E. PRATT* \\ From the Departments of Neuropathology and Biochemistry, Institute of Psychiatry, Maudsley Hospital, London
}

The histological study of phosphatase distribution began when Gomori (1939) and Takamatsu (1939) independently published a technique for the demonstration of alkaline phosphatase in tissue sections. This method was extended to the localization of acid phosphatase under normal and pathological conditions (Gomori, 1941). Wolf, Kabat, and Newman (1943) studied the distribution of this enzyme with special reference to the nervous system, and Bodian and Mellors (1944) found changes in phosphatase activity in chromatolytic nerve cells. Critical studies by Danielli (1946) have confirmed the validity of the general technique, but Stafford and Atkinson (1948) showed that there was a considerable loss of phosphatase activity during acetone or alcohol fixation. Doyle (1948) found that acid phosphatase was distinctly better preserved by dehydration in the frozen state than after such fixation. A procedure for freezing tissue at liquid air temperatures and dehydrating in a vacuum suggested by Altmann was developed by Gersh (1932) and subsequently modified by several investigators. Studies on the distribution of acid phosphatase in chemically fixed material have given diverse results and it would seem, therefore, that tissue prepared by a freeze-drying procedure and submitted to a modification of the Gomori technique, taking into account the criticisms by Martin and Jacoby (1949) and Danielli (1950). would yield more reliable results. In the application of such a method it is necessary to adapt the Altmann-Gersh technique to preserve, as far as practicably possible, the histological integrity of brain tissue. In addition, the significance of the final result depends upon the provision of optimal conditions for the activity of the enzymes under investigation.

The non-specific phosphatase demonstrable by glycerophosphate has formed the subject of much

* Holder of research grant from the Medical Research Council under the Mapother Bequest. earlier work in chemically fixed tissue. Other more specific. phosphatases have been observed by biochemical methods. Those acting on adenosine esters are of particular importance in view of the participation of these compounds in a number of metabolic processes. A 5-nucleotidase has been described in extracts of brain (Reis, 1934), and adenosine monophosphate (5-adenylic acid) was used in this study to demonstrate it. The importance of adenosinetriphosphatase has been established, and Meyerhof (1948) has attributed a controlling role to it in glycolysis. This enzyme was found to be bound to particulate elements of brain homogenates (Meyerhof and Wilson, 1948). The present paper describes and illustrates results obtained from localizing in brain tissue the sites of enzymatic phosphate liberation from glycerophosphate at

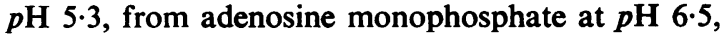
and from adenosine triphosphate at $p \mathbf{H}$ 6.5.

\section{Method}

The freeze-drying technique used consisted in rapid freezing of thin slices of tissue followed by removal of the ice by sublimation under high vacuum.

Normal, young, adult male and virgin female white rats were used. The animals were anaesthetized with ether, and the calvarium was removed. The brain was then enucleated; $2 \mathrm{~mm}$. thick coronal sections were cut with new safety razor blades and frozen in isopentane (Simpson, 1941) at $-35^{\circ} \mathrm{C}$. within $\cdot 20$ seconds.

After not more than 10 minutes the blocks were removed with appropriately shaped lengths of platinum wire which were themselves first cooled. The pieces of brain were then quickly laid on a bed of degassed paraffin wax (m.p. $49^{\circ} \mathrm{C}$.) in a specially designed glass tube which attaches to a phosphorus pentoxide trap mounted on an Edwards $2 \mathrm{~S} .50$ high vacuum pump. The tube was then surrounded by a vacuum flask containing phenyl ethyl ether (phenetole) brought down to a temperature of $-78^{\circ} \mathrm{C}$. by means of solid carbon dioxide. The pump was started, and drying continued for three days. After about six hours the phenetole bath had risen to a temperature of $-30^{\circ} \mathrm{C}$. at which it was maintained by the periodic addition of solid carbon dioxide. At the 
end of 72 hours the vaccum flask was removed and the material was left for about two hours to warm up toward room temperature. The tube was then isolated from the pump by closing a valve. The wax was melted cautiously by means of a water bath and embedding continued for 15 minutes under water pump pressure.

Paraffin blocks were made in the usual way. All the paraffin material was stored at $-10^{\circ} \mathrm{C}$. in a dessicator. Sections, $7-15 \mu$ thick, were cut on the same day on which they were required for the chemical procedures from blocks stored for less than a week. The blocks were cooled before being cut on the microtome as the resulting rigid sections could be more easily mounted onto albumenized slides without the use of water.

Dewaxing was carried out immediately before incubation in petroleum ether (boiling range $80-100^{\circ} \mathrm{C}$.) for two minutes followed by two rinses in isopentane (boiling range $27-31^{\circ} \mathrm{C}$.). The sections dried immediately on contact with air and became paper-white within two to five seconds. They were then thrust into the incubation media (previously warmed to $37^{\circ} \mathrm{C}$.) with a sharp movement to avoid the adhesion of air bubbles.

The general procedure was to incubate these specially prepared sections in media containing a single phosphoric acid ester, from which the active enzyme split phosphate. Lead ions were added to the incubation medium so that this phosphate was precipitated at the site of liberation as lead phosphate. This precipitate was then converted to a visible product.

The substrate media were prepared directly before use. They each contained a phosphoric acid ester, a lead salt required to precipitate the liberated phosphate and a buffer.

The composition of the media is given in Table I and they are compared in Table II.

Coplin staining jars containing the slides in 30 to $60 \mathrm{ml}$. of medium were placed in an incubator set to $37^{\circ} \mathrm{C}$. Sections were removed at various intervals for treatment whereby the precipitated phosphate was converted to lead sulphide which is brown.

The slides were washed for $\mathbf{1 0}$ minutes in four changes of iced distilled water, placed in cold dilute yellow ammonium sulphide solution (1 ml. in $50 \mathrm{ml}$. of water) for two minutes, and rinsed again in iced distilled water. The sections were rapidly dehydrated through the alcohols, followed by $15 \%$ cyclohexanol in petroleum ether, and by petroleum ether (boiling range $80^{\circ}-100^{\circ} \mathrm{C}$.) alone. They were mounted in " clearax " (Gurr) dissolved in petroleum ether.

Glass-distilled water was used throughout. The adenosine triphosphate (Boots) used in this work was stored as the barium salt $\left(\mathrm{Ba}_{2} \mathrm{ATP} 4 \mathrm{H}_{2} \mathrm{O}\right)$ at $-78^{\circ} \mathrm{C}$. When required it was reprecipitated to remove the decomposition products and converted to the sodium salt by the use of an ion exchange resin (Bailey, 1950). Zeokarb 216 resin $(2.5 \mathrm{~g}$.) in a $15 \mathrm{ml}$. column was converted to the acid form with $5 \mathrm{~N}-\mathrm{HCl}$ and washed with glass-distilled water until the $p \mathbf{H}$ of the effluent was greater than 5.0. All subsequent operations were carried out at $0^{\circ} \mathrm{C}$. The barium salt of adenosine triphosphate (200 mg.) was dissolved in $2 \mathrm{~N}-\mathrm{HCl}(5 \mathrm{ml}$.) and diluted with water $(10 \mathrm{ml}$.). The solution was brought to $p H$
TABLE I

COMPOSITION OF THREE MEDIA EMPLOYED

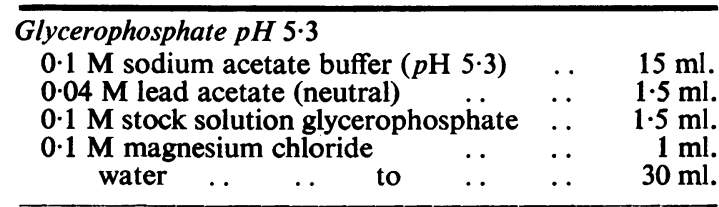

Adenosine triphosphate $\mathrm{pH} 6.5$

$0.002 \mathrm{M}$ stock solution adenosine triphosphate .. .. .. . $7.5 \mathrm{ml}$. $0 \cdot 1 \mathrm{M}$ sodium succinate buffer $(p \ddot{H} 6.5) \quad \ldots \quad 15 \mathrm{ml}$

$0.04 \mathrm{M}$ lead acetate (neutral) $\quad . \quad \ldots .00 .75 \mathrm{ml}$. water $\quad$. to $\quad \ldots \quad 30 \mathrm{ml}$.

Adenosine monophosphate pH 6.5

$0.005 \mathrm{M}$ stock solution adenosine mono-

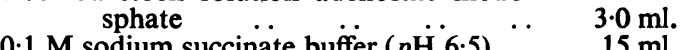
$0.04 \mathrm{M}$ lead acetate (neutral) $(p \mathrm{H} \mathrm{6.5}) \ldots \quad 15 \mathrm{ml}$.

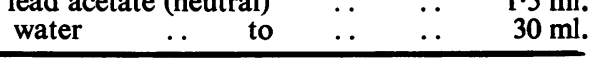

TABLE II*

COMPARISON OF THREE MEDIA EMPLOYED

\begin{tabular}{c|c|c|c}
\hline $\begin{array}{c}\text { Phosphate } \\
\text { Ester }\end{array}$ & $\begin{array}{c}\text { Glycero- } \\
\text { phosphate }\end{array}$ & $\begin{array}{c}\text { Adenosine } \\
\text { Triphosphate }\end{array}$ & $\begin{array}{c}\text { Adenosine } \\
\text { Mono- } \\
\text { phosphate }\end{array}$ \\
\hline$p \mathrm{H} .$. & 5.3 & 6.5 & 6.5 \\
\hline Ester $\ldots$ & 0.005 & 0.0005 & 0.0005 \\
\hline \begin{tabular}{c}
$\mathrm{Pb} .++\ldots$ \\
\hline Mg. $++\ldots$
\end{tabular} & 0.002 & 0.001 & 0.002 \\
\hline $\begin{array}{c}\text { Buffers : } \\
\text { Acetate .. } \\
\text { Succinate }\end{array}$ & 0.05 & - & - \\
\hline
\end{tabular}

* All figures in molar concentration.

6.5 with $\mathrm{N}-\mathrm{NaOH}$ and centrifuged. The washed precipitate was redissolved in $3 \mathrm{ml}$. of $2 \mathrm{~N}-\mathrm{HCl}$ and $5 \mathrm{ml}$. of water. This solution was passed through the resin column and washed through with water $(25 \mathrm{ml}$.). The effluent was neutralized with $\mathrm{N}-\mathrm{NaOH}$, diluted to $50 \mathrm{ml}$., and stored at $-78^{\circ} \mathrm{C}$. After analysis the solution was diluted so that it contained $124 \mu \mathrm{g}$. labile phosphorus per millilitre. Commercial samples of adenosine monophosphate (B.D.H.) were sufficiently pure and were used as $0.005 \mathrm{M}$ aqueous solution neutralized with $\mathrm{NaOH}$ and stored at $-78^{\circ} \mathrm{C}$. Glycerophosphate containing a mixture of approximately equal parts of the $\alpha$ and $\beta$ isomers was of sufficient purity. The stability of the stock solutions was checked by frequent $p \mathrm{H}$ determinations.

Incubation periods at $37^{\circ} \mathrm{C}$. covered a wide range of times. Sections were removed at intervals, usually forming a logarithmic series : $10,20,40$, and 80 minutes. These times were found to be suitable for adenosine 
triphosphate and glycerophosphate but for adenosine monophosphate a range of 10 to 40 minutes was adequate.

After preliminary work on a large number of animals these conditions were used to obtain the results to be described.

Rapid freezing ensures accurate localization by reducing possible enzyme diffusion and conserves maximum activity. The anaesthetized brain is less liable to stimulation during sectioning and freezing. An initial freezing temperature of $-65^{\circ} \mathrm{C}$. for $2 \mathrm{~mm}$. sections was least liable to cause tissue damage and was consistent with good histology. Adequate tissue preparations also depend upon the duration of vacuum drying which appears not to be critical, but three days under the conditions described gave satisfactory results.

The time and temperature of embedding were not varied. The paraffin blocks retained their activity in storage without appreciable loss, whereas microtome sections deteriorated rapidly. Water and the aqueous alcohol solutions used in the usual dewaxing processes were found to have a detrimental effect on the experimental material. This difficulty was overcome by the use of a low boiling point wax solvent.

The medium containing glycerophosphate was substantially the same as that described by Gomori (1941, 1946). The other media were found experimentally to provide optimal conditions for qualitatively different staining in the minimum time. Inconsistent results were obtained when the adenosine triphosphate used in the incubation medium had not been reprecipitated. Variation of the $p H$ level of the substrate media within the acid range did not alter the characteristics of the localizations but retarded the reaction. The short incubation times made possible by preserving enzyme activity and the employment of optimal conditions reduced the possibility of diffusion. Those elements of tissue left unstained by each of the three procedures at short incubation times took on stain at prolonged incubation periods so that differences in localization at first striking became progressively reduced.

Control of the tissue activity in the various media was obtained by omission of the phosphoric acid ester, by washing or heating the tissue, by chemical pretreatment with trichloracetic acid, and especially by the use of enzyme inhibitors acting at relatively low concentrations. Sodium fluoride $\left(10^{-3} \mathrm{M}\right)$ was used in control media with glycerophosphate and uranyl acetate $\left(10^{-3} \mathrm{M}\right)$ in the adenosine triphosphate and adenosine monophosphate control media. If the ester were omitted from the substrate medium the staining was amorphous and negligible in quantity. Complete suppression of staining could be produced by adding to the substrate medium the inhibitors in the concentrations stated.

\section{Results}

The following findings, which are sites of lead sulphide deposition, were observed consistently in 20 consecutive animals when the experimental conditions were accurately followed. Tissue from each animal was incubated with all the experimental and control media.
Glycerophosphate Substrate.-Sections incubated in this medium showed staining mainly in the neuronal cytoplasm (Fig. 1A).

The cerebral cortex showed the characteristic cortical cytoarchitecture extremely well. The cells were clearly defined and stood out sharply against an unstained background. Some dendritic processes stained for short distances from their cell bodies. The cytoplasm stained intensely, but the nucleus remained unstained although well demarcated. The nucleolus and some karyosomes were as darkly stained as the cytoplasm. In the pyriform lobe staining of nerve cells appeared deeper than elsewhere in the cortex. In the corpus striatum and diencephalon there was a pale staining of the background which was more pronounced in the thalamus and hypothalamus than in the striate body and globus pallidus. The nuclei within the thalamus and hypothalamus varied in their degree of staining, although individual cells differed in no discernible respect from cortical neurons. The supraoptic nucleus of the hypothalamus (Fig. 8), the nuclei paraventralis reuniens, and the medio-dorsalis of the thalamus were all darker than other diencephalic nuclei.

Throughout the midbrain, pons, and medulla neurons of the cranial nerve nuclei stained deeply and showed those details demonstrated by the cortical neurons (Fig. 2A).

In the cerebellum Purkinje cells and the basket fibres were almost selectively stained (Figs. 3A and 4). The nucleolus of the Purkinje cells stained most deeply, the nucleus next, and the cytoplasm least. The basket fibres were as deeply stained as the nucleoli of the Purkinje cells. The granules showed little staining and at the time when the basket fibres were deep brown they appeared as light brown discrete cells.

Glial cells were evident throughout the whole brain, but stained only moderately. At none of the incubation periods employed did they approach the depth of staining reached by neuronal cytoplasm or cerebellar basket fibres.

Nowhere in the brain were the walls of the parenchymal vessels seen at short incubation times, but at such times as would make the Purkinje cells dark brown the nuclei of vessels walls appeared. The nuclei of meningeal vessel walls appeared darker than those of the smaller parenchymal vessels. All elements of the choroid plexus showed deep staining. The nuclei of ependymal cells lining. the ventricles, unlike neuronal nuclei, showed greater staining than the cytoplasm of these cells.

Apart from the basket fibres and the proximal parts of the dendrites of larger neurons no other fibres could be made out when tissue was incubated 
for less than three hours: prolonged incubation led to fibre staining.

Adenosine Triphosphate Substrate--All nuclei, wherever situated in the brain, appeared to show staining in some degree. Just as in material incubated with glycerophosphate the cytoplasm stood out in clear contrast to an unstained background, tissue incubated with adenosine triphosphate for short incubation times showed clearly demonstrable nuclei alone (Fig. 1B).

Most deeply stained were muscle nuclei in vascular walls, nuclei of ependymal cells, neuronal nucleoli and the astrocytes. At short incubation periods nuclei of vascular walls, neuronal nucleoli, and astroglia appeared to be the on!y elements demonstrable. Longer incubation periods of between 40 and 60 minutes produced staining of the neuronal nuclei but these nuclei remained lighter than glial nuclei. Neuronal nucleoli, however, were as dark as the glial etements (Fig. 2B). Interfascicular oligodendroglia had the same depth of staining as the neuronal nuclei.

When tissue was incubated with glycerophosphate some diencephalic nuclei stained more deeply than others, but with this substrate there was no variation in their degree of staining. In the cranial nerve nuclei the cytoplasm of individual cells showed slight staining but more than the cytoplasm of cortical or diencephalic neurons.

In the cerebellum the glial elements of the molecular layer were intensely stained and consequently very deep brown, and those glial cells in close association with the Purkinje cells were darker than the remaining cells (Figs. 3B and 5). At longer incubation times the Purkinje cell cytoplasm was only a moderate brown, but the nuclei were darker than the cytoplasm and the nucleoli darkest of all. There was usually an aggregation of darkly staining discrete particles at the perikaryon. The granular cells stained moderately and scattered through them were discrete deeply staining particles. The medullary centres of the folia were unstained but the glial cells between the fibres were a pale brown.

The choroid plexus was deeply stained in all its elements. Ependymal nuclei showed deep staining and nerve fibres none.

Adenosine Monophosphate Substrate.-Sections incubated in this medium showed staining mainly in the nerve fibres (Fig. 1c).

The corpus callosum and the fimbrial fibres of the hippocampus were the deepest staining structures and the fibres radiating from the corpus callosum were conspicuous. The larger nerve fibres appeared to stain more deeply than the finer ones, and those tracts considered to be most heavily myelinated appeared darkest.

The nerve cell bodies remained almost completely unstained (Fig. 2C). Only after incubation periods as long as $\mathbf{4 0}$ minutes did the neuronal nucleoli, but not cytoplasm, and glial nuclei appear.

In the cerebellum the Purkinje cells were left completely unstained except for the nucleolus (Fig. 3C), and were surrounded by intensely staining basket fibres. The molecular layer appeared as dark as the medullary centre, but neither of these elements approached the depth of staining to be seen in the hippocampal fimbria.

Ponto-cerebellar fibres and fibres of the spinal root of the trigeminal nerve were among the lightest of the fibre tracts (Fig. 6). Fibres of the cranial nerves in their intracerebral course were also very light. In the hippocampus the bands of fibres within the hilus of the Ammon's horn stained in varying degrees (Fig. 7).

At long incubation periods exceeding 60 minutes glial cells became visible, and at periods beyond that became as dark as callosal fibres. Cytoplasm of neurons was not seen even at these lengthy incubation periods.

The choroid plexus stained deeply in all its elements. The vascular walls stained only faintly at optimal incubation times.

\section{Discussion}

Three distinct localizations have been described depending upon which phosphoric acid ester was used in the incubation medium. That these findings represented the result of enzyme action was confirmed by the absence of staining on omission of the substrate ester and by its suppression with low concentrations of inhibitors. Marked differences in the sites of staining in the three cases precluded the possibility of phosphate formed by enzyme action being precipitated as lead phosphate at foci of crystallization in nuclei and other such formed elements. Thus, additional controls were available.

Previous work on this subject has been concerned largely with the localization of non-specific acid phosphatase. The varied results given by work carried out in the acid range on tissue fixed in formalin, acetone, or alcohol makes their assessment difficult, particularly in view of the considerable but uncertain destructive effect of these fixatives on the enzymes. A comparison of the results presented in this communication with those so far obtained by usual biochemical and centrifugation techniques is not strictly possible. Further, the microscopical appearances of frozen dried tissue 


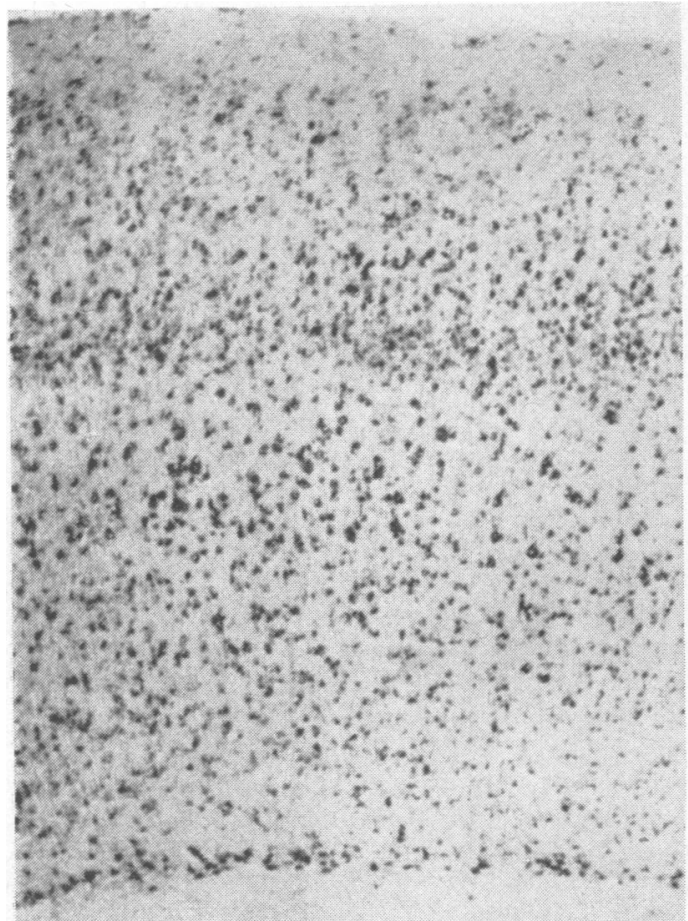

FiG. $1 a$

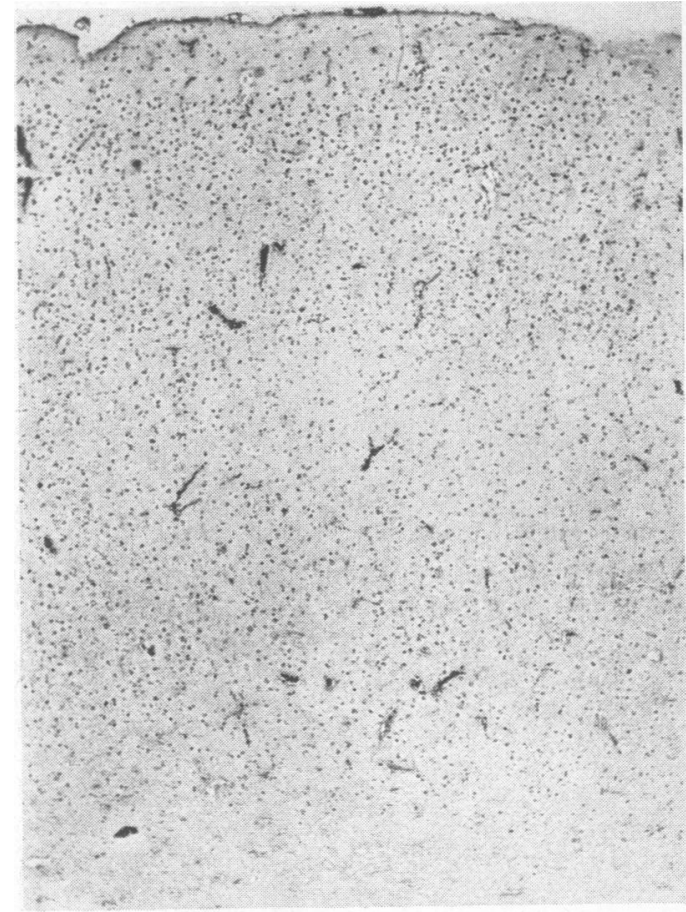

FIG. $1 b$

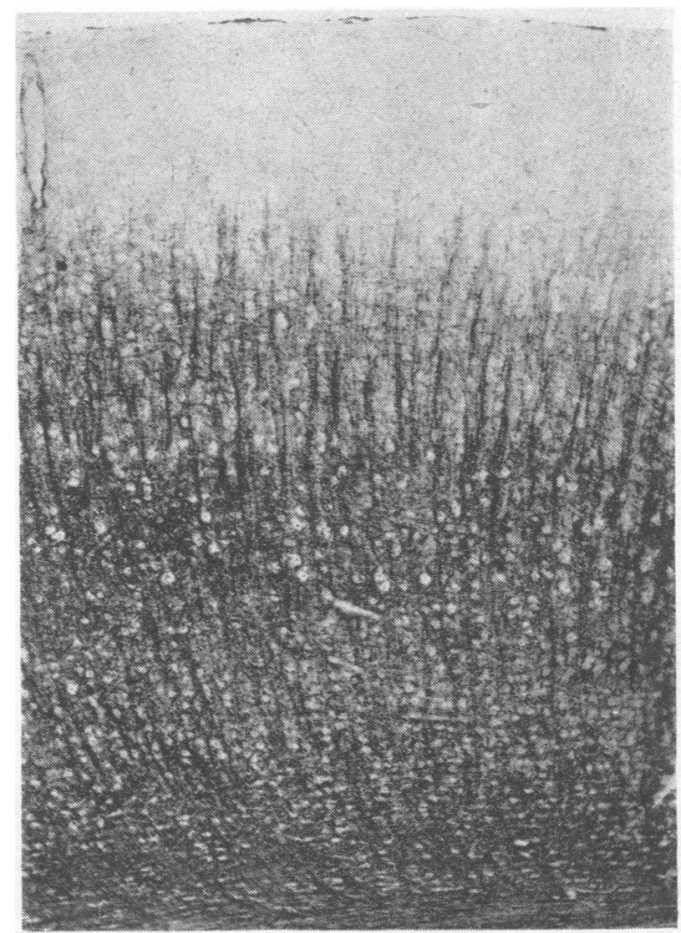

FIG. $1 c$

\section{Fig. 1: Cerebral Cortex $\times 50$}

a. Glycerophosphate substrate, showing deep staining of the neuronal cytoplasm and moderate glial staining.

b. Adenosine triphosphate substrate, showing staining of glial, neuronal, and vascular wall nuclei.

c. Adenosine monophosphate substrate showing staining of nerve fibres. Nerve cell bodies, except for their nucleoli, are left unstained. 


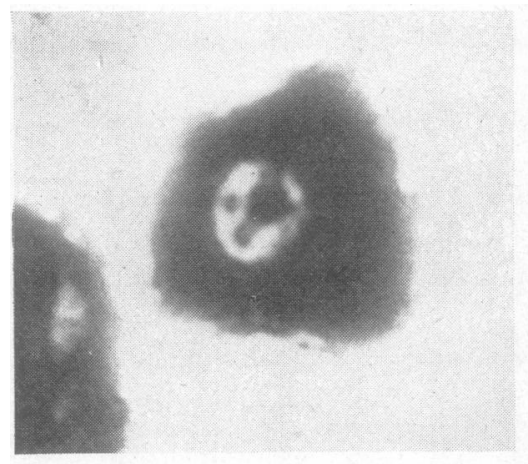

$a$

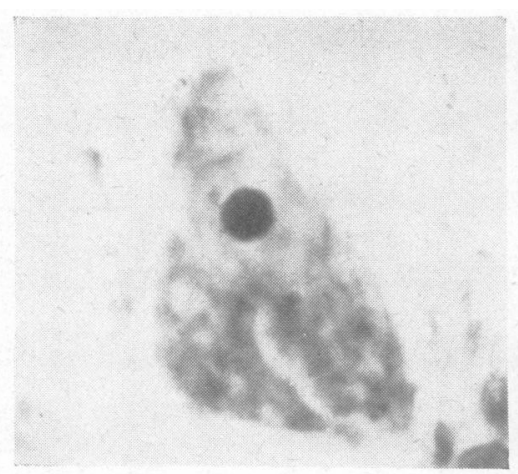

$b$

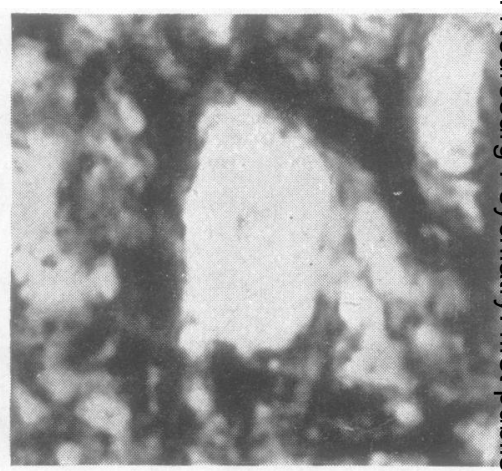

Fig. 2 : Single Neuron from Hypoglossal Nucleus $\times 500$

a. Glycerophosphate substrate, showing staining of the cytoplasm, nucleolus, and some karyosomes.

$b$. Adenosine triphosphate substrate, showing staining of the nucleolus and light staining of the cytoplasm.

c. Adenosine monophosphate substrate, showing, except for a faint nucleolus, an unstained nerve cell body.

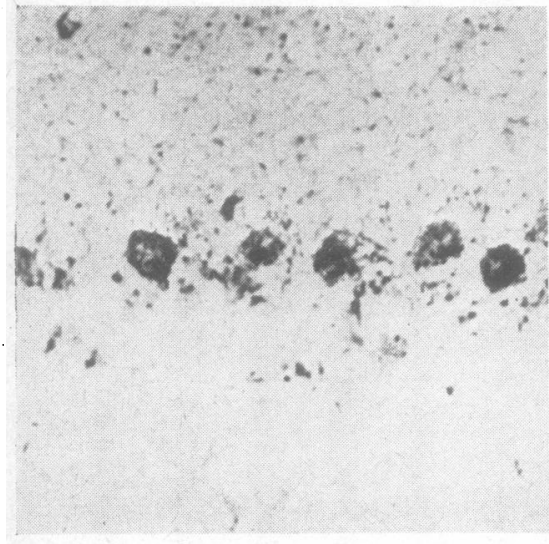

$a$

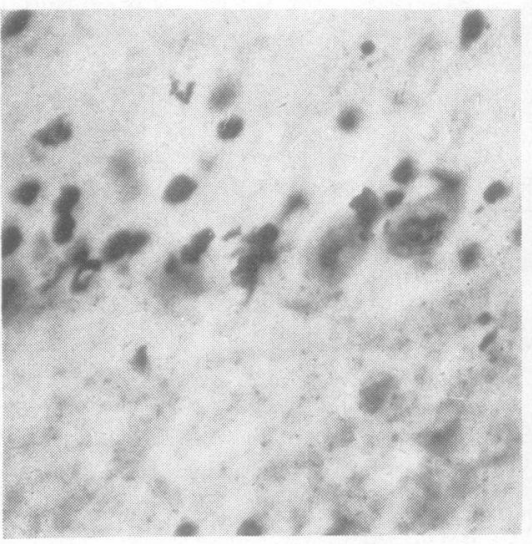

$b$

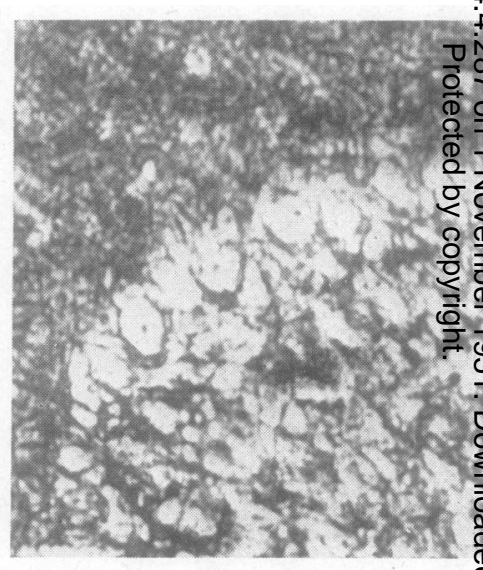

Fig. 3 : Cerebellar Cortex $\times 150$

$a$. Glycerophosphate substrate, showing staining of the Purkinje cells and basket fibres.

b. Adenosine triphosphate substrate, showing deep staining of the Bergmann glial and nucleoli of Purkinje cells.

c. Adenosine monophosphate substrate, showing staining of nerve fibres and nucleoli of Purkinje cells. 


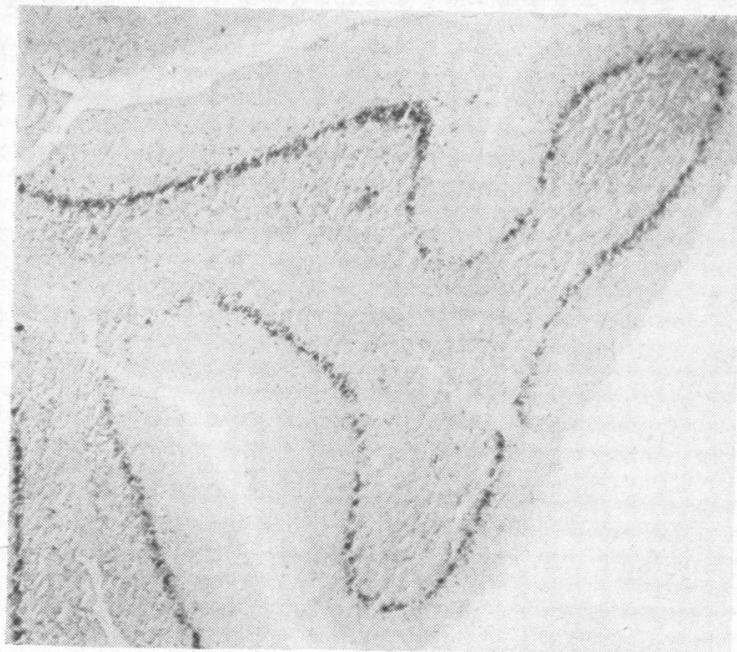

Fig. 4 : Cerebellar Cortex $\times 45$

Glycerophosphate substrate, showing almost selective staining of the Purkinje cells.

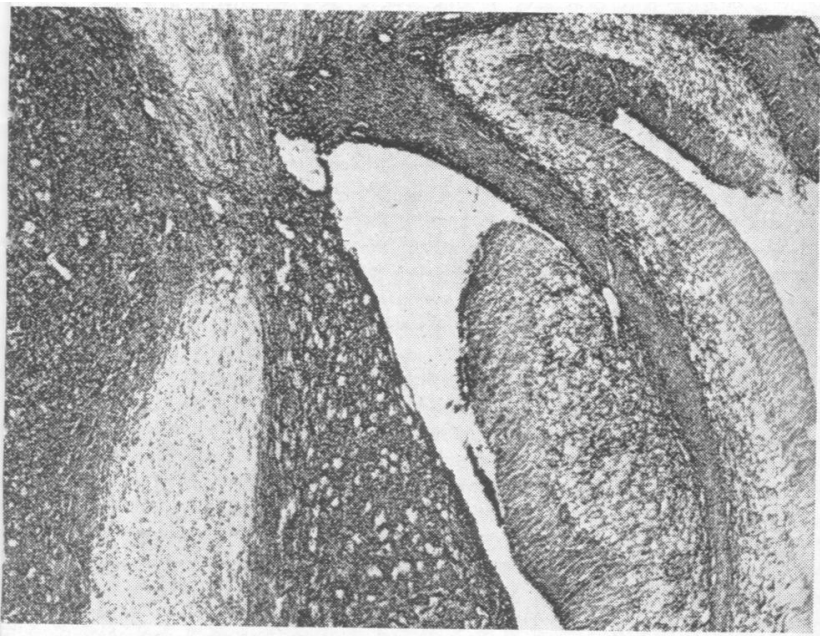

\section{6 : Ponto-Cerebellar Angle $\times 45$}

Adenosine monophosphate substrate, showing light staining of pontocerebellar fibres and the descending root of the trigeminal nerve. The medullary centre and molecular layer of the cerebellar cortex stain, whereas the granules and the nerve cell bodies of the ventral cochlear nucleus do not.

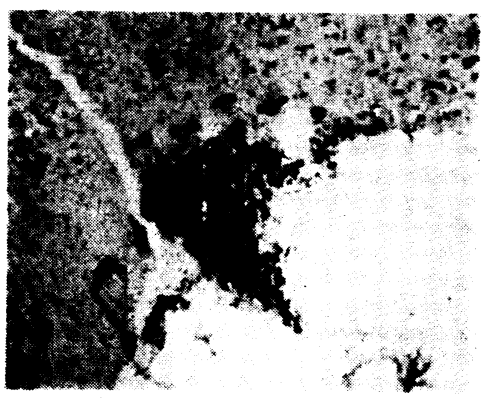

Fig. 8: Supraoptic Nucleus $\times 50$

Glycerophosphate substrate showing deep staining of the supraoptic nucleus.

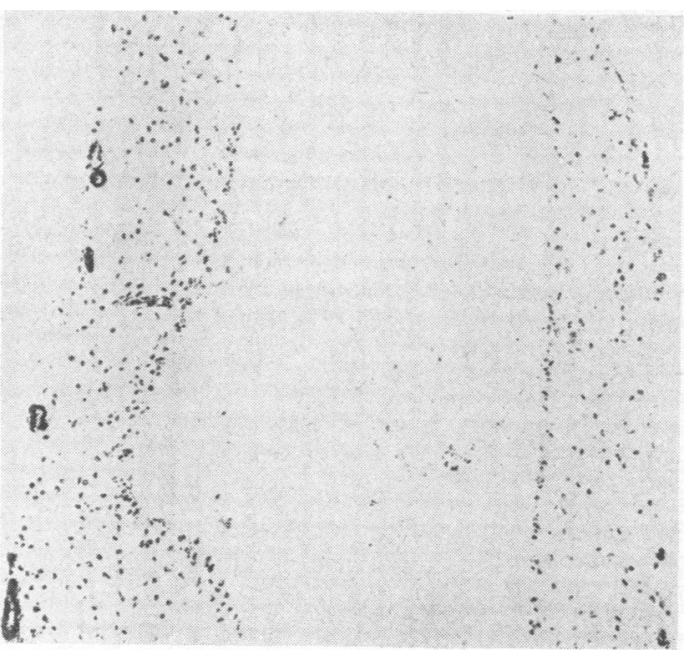

Fig. 5: Cerebellar Cortex $\times 70$

Adenosine triphosphate substrate, showing faintly staining glial cells in the medullary centre, an unstained granular layer, and deeply staining glial and vascular wall nuclei in the molecular layer.

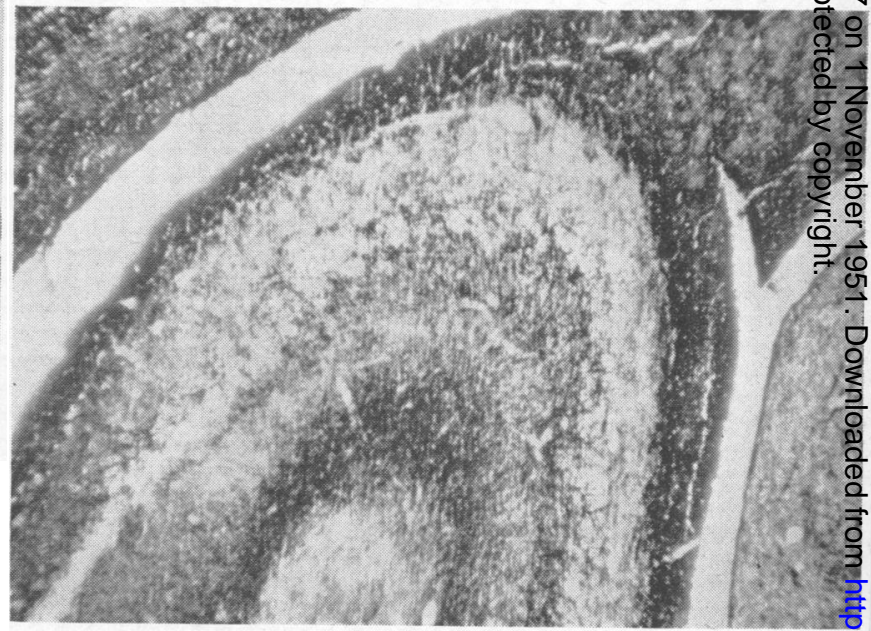

\section{Fig. 7 : Hippocampus $\times 40$}

Adenosine monophosphate substrate, showing bands of fibres stainini in varying degrees. 
do not entirely correspond with those found in the usual formalin-fixed material, a difference which warrants further study.

Various physiological processes are associated with the acid phosphatase activity of cells and, in general, protein formation is related to such activity. The metabolism of cellular nucleic acids necessarily involves the action of several enzymes : an example of this is provided by the study of the development of the Nissl substance. Chromatolysis after axon section is accompanied by a great increase in non-specific acid phosphatase and this increase is also demonstrable during regeneration. Although earlier work on the localization of nonspecific acid phosphatases gave divergent results the findings described in this paper substantiate some of the previous conclusions.

The idea that the oligodendrocyte is in some way concerned with the maintenance of the myelin sheath is widely accepted. It has been postulated similarly for a considerable time and recently re-stated by Folch (1947) that the astrocytes, particularly the protoplasmic type, function in an analogous way to the nurse cells found among insecta : that is, cells whose function it is to maintain other cells. In view of this hypothesis it is of interest that astroglial cells show high enzyme activity when incubated with adenosine triphosphate. This energy-rich ester is important in the metabolism of the brain, and yields some 12,000 calories per mol on hydrolysis.

Comment on the presence of an enzyme-splitting adenosine monophosphate in the nerve fibres is not possible until more is known about the physio$\log$ cal significance of this compound.

The study of the nervous system by the use of these new techniques is still in the early stages of development and established findings are relatively few. Such methods, however, seem to us to hold promise for the future.

\section{Summary}

The histological distribution of acid phosphatase activity has been studied in rapidly frozen and vacuum-dehydrated brain tissue. The main site of enzymatic phosphate liberation from glycerophosphate was in the cytoplasm of neurons. Glial and neuronal nuclei were the main site of adenosine triphosphate cleavage, and adenosine monophosphate was split mainly in nerve fibres.

We are grateful to Professor Alfred Meyer and Dr. H. McIlwain for their interest in and encouragement of this work. Technical assistance was ably rendered by Miss Joyce Hinton.

\section{REFERENCES}

Bailey, K. (1949). Biochem. J., 45, 479.

Bodian, D., and Mellors, R. C. (1944). Proc. Soc. exp. Biol., N.Y., 55, 243.

Danielli, J. F. (1946). J. exp. Biol., 22, 110. (1950). Nature, Lond., 165, 762.

Doyle, W. L. (1948). Proc. Soc. exp. Biol., N.Y., 69, 43. Folch, J. (1947). In "Psychiatric Research". Harvard University Press.

Gersh, I. (1932). Anat. Rec., 53, 309.

Gomori, G. (1939). Proc. Soc. exp. Biol., N. Y., 42, 23. (1941). Arch. Path., 32, 189. (1946). Amer. J. clin. Path., 16, 347.

Martin, B. F., and Jacoby, F. (1949). J. Anat., Lond., 83, 351

Meyerhof, O. (1948). Experimentia, Basel, 4, 169.

-, and Wilson, J. R. (1948). Arch. Biochem. 17, 153.

Reis, J. (1934). Bull. Soc. Chem. biol., 16, 385.

Simpson, W. L. (1941). Anat. Rec., 80, 173.

Stafford, R. O., and Atkinson, W. B. (1948). Science, 107, 279.

Takamatsu, H. (1939). Trans. Jap. path. Soc., 29, 492.

Wolf, A., Kabat, E. A., and Newman, W. (1943). Amer. J. Path., 19, 423. 